\title{
Correction to: Bioreactor Scale-Up
}

Aydin Berenjian

\section{Correction to:}

Chapter 7 in: A. Berenjian (ed.), Essentials in Fermentation Technology, Learning Materials in Biosciences, https://doi.org/10.1007/978-3-030-16230-6_7

On page 224, Chap. 7-Bioreactor Scale-Up, the numbers calculated for kLa were erroneously published. This has been corrected in this version and it should be read as:

"and from Eq. 7.4b, for 200 rpm, we have:

$$
k_{\mathrm{L}} a=0.3714 \mathrm{~min}^{-1} \text { or } 22.28 \mathrm{~h}^{-1}
$$

And for $400 \mathrm{rpm}$, we have:

$$
k_{\mathrm{L}} a=0.6828 \mathrm{~min}^{-1} \text { or } 40.96 \mathrm{~h}^{-1 ”}
$$

